\title{
Description of local adaptation of national guidelines and of active feedback for rationalising preoperative screening in patients at low risk from anaesthetics in a French university hospital
}

E Capdenat Saint-Martin, P Michel, J M Raymond, H Iskandar, C Chevalier, M N Petitpierre, L Daubech, M Amouretti, P Maurette

\begin{abstract}
Objective-To describe the effect of local adaptation of national guidelines combined with active feedback and organisational analysis on the ordering of preoperative investigations for patients at low risk from anaesthetics.

Design-Assessment of preoperative tests ordered over one month, before and after local adaptation of guidelines and feedback of results, combined with an organisational analysis.

Setting-Motivated anaesthetists in 15 surgical wards of Bordeaux University Hospital, Region Aquitain, France.

Subjects-42 anaesthetists, 60 surgeons, and their teams.

Main outcome measures-Number and type of preoperative tests ordered in June 1993 and 1994, and the estimated savings. Results-Of 536 patients at low risk from aneasthetics studied in 1993 before the intervention $80 \%$ had at least one preoperative test. Most $(70 \%)$ tests were ordered by anaesthetists. Twice the number of preoperative tests were ordered than recommended by national guidelines. Organisational analysis indicated lack of organised consultations and communication within teams. Changes implemented included scheduling of anaesthetic consultations; regular formal multidisciplinary meetings for all staff; preoperative ordering decision charts. Of 516 low risk patients studied in 1994 after the intervention only $48 \%$ had one or more preoperative tests ordered $(p<0.05)$. Estimated mean (SD) saving for one year if changes were applied to all patients at low risk from anaesthesia in the hospital 3.04 (1.23) $\mathrm{mFF}$.
\end{abstract}

Conclusions-A sharp decrease in tests ordered in low risk patients was found. The likely cause was the package of changes that included local adaptation of national guidelines, feedback, and organisational change.

(Quality in Health Care 1998;7:5-11)

Keywords: preoperative tests; medical audit; guidelines

Introduction

Each year in France over 3.5 million anaesthetics are given to people undergoing surgical, obstetric, or diagnostic procedures. Most are for patients for whom an anaesthetic carries very little risk and are in class I of the American Society of Anaesthesiology classification of anaesthetic risk (ASA1). ${ }^{12}$ Routine preoperative tests for this large group of fit patients have been shown to have little diagnostic use and do not add to the safety of the anaesthetic..$^{3-9}$ Despite numerous recommendations arguing for selective use of these tests-for example, those of the French Agence Nationale pour le Developpement de l'Evaluation Medicale (ANDEM) and the Societe Francaise d'Anesthesie Reanimation $(\mathrm{SFAR})^{10}$-routine preoperative tests on fit people are still requested in many French hospitals and are responsible for unnecessary excessive costs. ${ }^{210}{ }^{11}$ Although $95 \%$ of French anaesthetists in 1991 said they knew about the national guidelines for preoperative testing and $80 \%$ were in favour of more targeting, there is evidence that their practice has not changed fundamentally since the publication of the guidelines. ${ }^{2}$ Various strategies have been proposed for modifying professional behaviour and implementing the guidelines. Some - such as training alone or passive feedback-have not proved very effective ${ }^{1624}$ whereas others based on active feedback of data have had a better impact, particularly on ordering behaviour. ${ }^{15-18}$

The impact of feedback on professional behaviour particularly on ordering investigations when included as part of the process of medical audit has been shown. ${ }^{12-17}$ The development of guidelines that incorporate scientific data with local practice can be used to change clinical practice. ${ }^{161819}$ We were aware that the number of preoperative tests in our hospital was high and we were keen to implement change that would reduce the number of unnecessary tests. To do this we decided as well as promoting the local adaptation of the national guidelines to look critically at the organisational aspects of clinical behaviour and to implement a package of initiatives that linked measurement and active feedback with an analysis of the organisation of preoperative care. This paper describes that process of implementing those initiatives, and their impact on the requests for preoperative tests for fit ASA I patients undergoing surgery in 15 wards in the University Hospital of Bordeaux, France.
Accepted for publication 21 January 1998 
Methods

CONTEXT

Our university hospital has 3094 short stay beds. In the surgical division there are 108 anaesthetists and 144 surgeons working in 36 wards. In 1992, 55687 anaesthetics were performed in this unit of which, working from national figures ${ }^{1}$ we estimated about 22000 were for fit ASA1 patients. The project took place in 1993-4 There was no significant staff turnover in this time except for the residents who change wards every six months.

APPROACH

The first step was to set up a working group that included a coordinating anaesthetist, physicians, other anaesthetists, a public health physician, chief nurses, hospital managers, an economist, and an organisational manager who was on the staff of our hospital in collaboration with the national agency ANDEM.

The coordinating anaesthetist (PM) of our working group is one of four directors of anaesthetics at the hospital. He discussed the project with all anaesthetists in the 36 ward block. Forty two anaesthetists who were all motivated in that they had all indicated keenness to participate were involved in the project, which focused on the ASA1 patients cared for on the 15 wards where all anaesthetists had agreed to participate. These wards perform $40 \%$ of the total surgical activity in our hospital. Nine departments were represented (orthopaedics, digestive and vascular surgery, paediatrics, gynaecology, obstetrics, urology, ear nose and throat, ophthalmology, endoscopy). All 60 surgeons working in these 15 wards, the residents, and the nurses were informed about the project.

SAMPLE SIZE

The percentage of low risk patients for whom no preoperative tests were ordered was estimated, from published work, to be about $20 \%{ }^{2}$ To show unambiguous evidence of an improvement in practice we thought that following the intervention the proportion of patients for whom no preoperative tests were ordered needed to increase to $30 \%$. With an $\alpha$ risk of 0.05 and a power of $95 \%$, we calculated that we needed at least 423 patients in each group, for a one tailed test. From the activity data from the 15 wards we calculated that measurement periods of one month would be needed to be sure of including this number of patients.

FIRST MEASUREMENT

An initial prospective assessment of the use of preoperative tests on all fit low risk patients over one month was done in June 1993, before the first stage of the implementation of changes and the development and agreement of locally adapted guidelines. The classification of risk from anaesthesia was assessed independently by each anaesthetist just before anaesthesia and the following data were also collected by the anaesthetist: degree of emergency, organisation of anaesthetic consultation, types of anaesthesia and surgery, status and profession of the person who ordered preoperative tests (indi- vidual people were not identified), and any preoperative tests ordered. Preoperative tests included in the study were: chest radiography, electrocardiogram, coagulation studies, haemoglobin, blood group, electrolytes, glucose, urea, creatinine, and hepatic enzymes. Details of recovery room perioperative mortality were also collected. Anaesthetists involved in the study were asked to complete brief questionnares about their patients. This process was helped by the involvement of one of the resident anaesthetists who visited each ward daily to help anaesthetists to collect data and maintain motivation. Surgeons, other residents, and nurses were not involved in data collection.

\section{DEVELOPMENT OF GUIDELINES}

During a two month period the national guidelines for preoperative investigation of patients were discussed in each department and each department was asked to adapt the guidelines to meet local circumstances and surgical specificity. This process had three phases.

\section{First phase}

The coordinating anaesthetist presented the national-ANDEM and SFAR-guidelines at a meeting of all anaesthetists-seniors and residents - in each of the nine departments, recorded who attended these meetings.

\section{Second phase}

The coordinator conducted a further two hour meeting in each department when the national guidelines were presented again-this time focusing on the level of evidence-and included a discussion of the framework for local guidelines which advocated the general rule that no preoperative tests should be ordered for patients at low risk from anaesthesia but allowed for several exceptions to be decided upon by common consent in each department. Consensus about exceptions for each department was reached at the end of the meeting. The second meeting was held about a month after the first to give the departments time to consider their response to the guidelines.

\section{THIRD PHASE}

Each anaesthetist received the departmental guidelines and had to approve them.

The difference between the number of tests ordered during the first assessment and those expected according to local guidelines was analysed by the working group. These results were sent back to all members of each department in several ways. Firstly, an abstract was sent to each professional working on the 15 wards. Secondly, the results were also communicated by the working group of all the anaesthetists working on the wards involved in the study, and discussed at a meeting in November 1993. Finally, each department organised a submeeting to discuss these results to take into account the opinion of the anaesthetists, surgeons, and technical staff.

ORGANISATIONAL MANAGEMENT

The organisational manager (MNP) studied preoperative ordering and the communication 


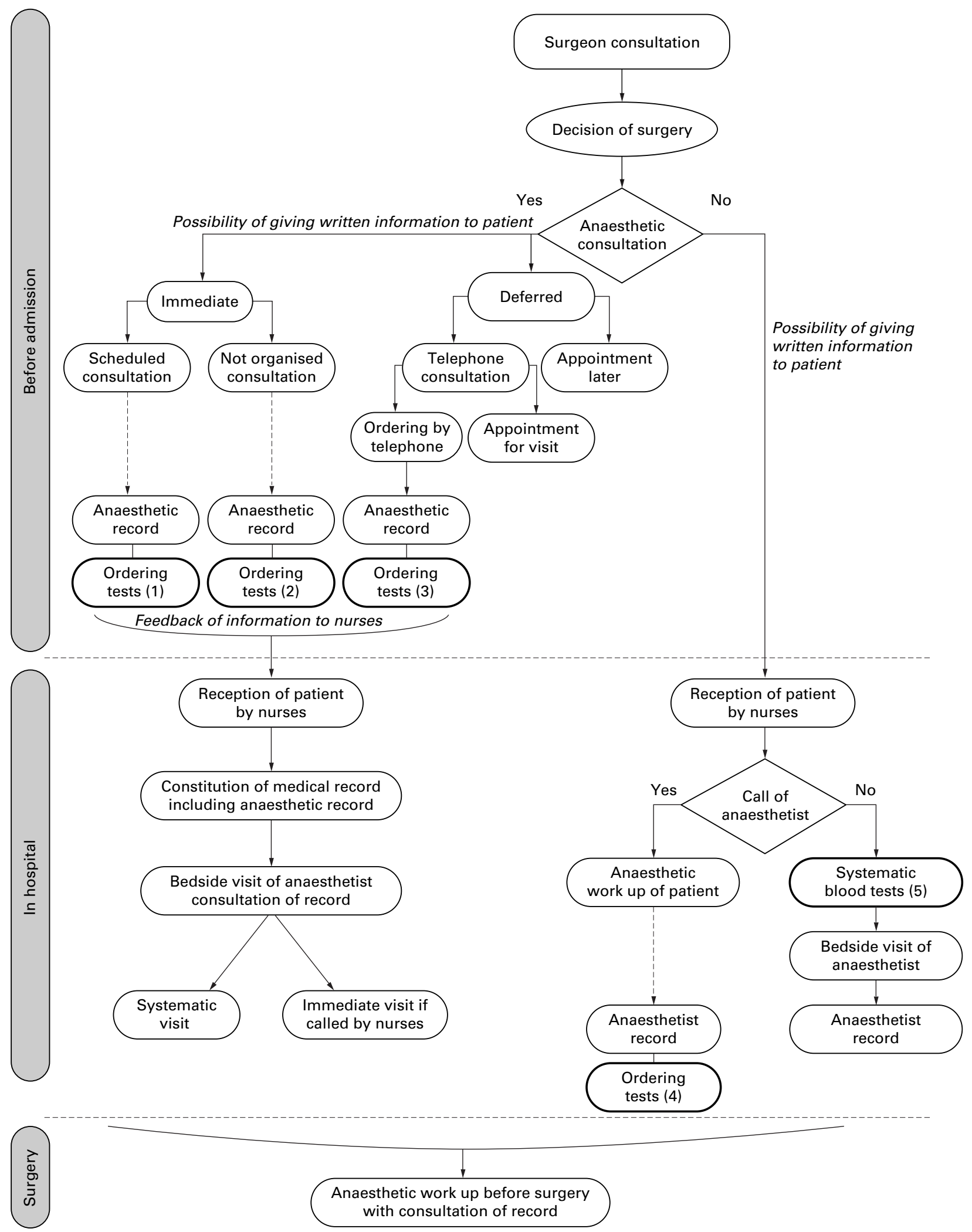

Figure 1 Algorithm used for assessment of the ordering processes for preoperative tests before implementing changes, Bordeaux University Hospital, France. Ordering tests 1, 2, 3, 4, and 5: processes of ordering preoperative screening by anaesthetists and other professionals.

processes in each department. During a meeting with the principle anaesthetists in each department involved in the project she analysed and discussed the following: (a) who ordered preoperative investigations, when, where, and how they were ordered, $(b)$ the mode of communication between staff members, and (c) how anaesthetic consultations were organised.

For each department, MNP constructed an algorithm of the consultation and ordering processes to facilitate understanding of weak- 


\begin{tabular}{|c|c|c|c|c|c|c|c|c|c|}
\hline & & $\begin{array}{l}\mathrm{T} / \\
\mathrm{SA}\end{array}$ & $\mathrm{Hb}$ & $\begin{array}{l}\text { PT/ } \\
\text { PTT }\end{array}$ & $\begin{array}{l}\mathrm{Plt} / \\
\mathrm{BT}\end{array}$ & $\begin{array}{l}\text { Elec/ } \\
\text { Glu }\end{array}$ & $\begin{array}{l}\text { BUN/ } \\
\text { Creat }\end{array}$ & $\begin{array}{c}x \text { Ray } \\
\text { film }\end{array}$ & ECG \\
\hline \multirow[t]{2}{*}{ Surgical procedures } & Minor & & & & & & & & \\
\hline & Major & & & & & & & & \\
\hline \multirow[t]{3}{*}{ Patient's age $(y)$} & $<40$ & & & & & & & & \\
\hline & $40-70$ & & & & & & & & \\
\hline & $>70$ & & & & & & & & \\
\hline \multirow[t]{7}{*}{ Associated pathology } & Cardiovascular & & & & & & & & \\
\hline & Pulmonary & & & & & & & & \\
\hline & Cancer & & & & & & & & \\
\hline & Hepato-biliary & & & & & & & & \\
\hline & Renal & & & & & & & & \\
\hline & Bleeding disorder & & & & & & & & \\
\hline & Diabetes & & & & & & & & \\
\hline \multirow[t]{4}{*}{ Medications } & Diuretics & & & & & & & & \\
\hline & Digitalis & & & & & & & & \\
\hline & Corticosteroids & & & & & & & & \\
\hline & Anticoagulants & & & & & & & & \\
\hline
\end{tabular}

Figure 2 Example of a decision chart displayed to help anaesthetists in ordering preoperative tests for patients at low risk and at higher risk from anaesthesia in the department of urology, 1994, University Hospital of Bordeaux, France.

$T / S A=$ blood typing and screening for unexpected antibodies; Hb=haemoglobin; PT/PTT=prothrombin time and partial thromboplastin time; Plt/BT=platelet count and bleeding time; Elec/Glu $=\mathrm{Na} a^{+}, \mathrm{K}^{+}, \mathrm{Cl}, \mathrm{CO}{ }_{2}$, proteins, blood glucose; $B U N /$ creat $=$ blood urea nitrogen and creatinine.

nesses in the system. Six months after the start of the project in January 1994, the working group arranged meetings with the anaesthetists in each department to discuss the points outlined by the organisational consultant and the results of the first set of measurements and to decide on changes in the light of these findings.

\section{SECOND MEASUREMENT}

A second measurement period took place in June 1994, about six months after implementation of change. The same process as for the first measurement was used to assess whether the process of change had resulted in improvement.

\section{ASSESSMENT OF ANY SAVINGS}

The mean cost of preoperative testing was calculated for the two measurement periods with standard costs based on the French National Nomenclature Generale des Actes Professionnels ${ }^{20}$ which gives costs for all standard investigations. The annual saving to the hospital was estimated by simply extrapolating from the savings estimated in our sample to the estimated total number of fit low risk patients operated on in this hospital in 1992 (22 000 low risk patients).

\section{STATISTICAL ANALYSIS}

Investigations for patients undergoing different types of anaesthesia and surgery performed during the two evaluation periods were compared by the $\chi^{2}$ test. The $\chi^{2}$ test was also used to assess the significance of changes in the proportion of patients for whom no tests were ordered and those who had perioperative adverse effects in the two test periods. The mean (SD) ages of children and adults is given and distributions by age groups were compared by the $\chi^{2}$ test.

\section{Results}

FIRST MEASUREMENT

During the first measurement period 536 low risk patients were included, representing $40 \%$ of the anaesthetic activity of the wards studied. Mean (SD) age for children ( $<18$ years) was 6.8 (4.9) years and for adults it was 36.3 (12.7) years.

Thirteen patients were noted to have minor perioperative events-for example, headache, vomiting, mild hypertension. No patient died.

One hundred and eight patients (20\%) did not have preoperative tests. Most preoperative tests were instigated by anaesthetists who ordered them for $70 \%$ of those patients who had preoperative tests; surgeons ordered tests for $8.4 \%$ of patients; nurses for $7.8 \%$; residents for $3.0 \%$, and general practitioners for $2.6 \%$. For $8.2 \%$ of patients the person ordering the tests was not indicated on the questionnaire.

Coagulation testing and haemoglobin were the tests ordered most often. When compared with local guidelines that had been agreed by the departments, tests for haemoglobin and coagulation, and chest radiography were carried out on twice as many patients than were indicated by the guidelines. Fibrinogen and hepatic enzyme tests, although not recommended by the anaesthetists, were sometimes ordered by them. These results were made known to all anaesthetists in the departments. The aim of the feedback was to make everyone aware of the difference between the actual pattern of test ordering and the agreed guidelines.

\section{ORGANISATIONAL ANALYSIS}

The analysis performed by the organisational manager in collaboration with the anaesthetists and their teams showed much variation in the processes of ordering and organisation in each department. Separate algorithms of these processes were produced for each department. 
Table 1 Comparison of age groups, type of anaesthesia, and surgery performed for patients at low risk from anaesthesia (ASA I) in the two samples (Fune 1993 and Fune 1994) in the University Hospital of Bordeaux, France

\begin{tabular}{lccc}
\hline & ASA I patients & & \\
\cline { 2 - 3 } & $\begin{array}{l}1993(n=536) \\
n(\%)\end{array}$ & $\begin{array}{l}1994(n=516) \\
n(\%)\end{array}$ & p Valuet \\
\hline Age group (y): & & & \\
$\quad<5$ & $129(24.25)$ & $110(21.32)$ & \\
$6-15$ & $123(23.12)$ & $153(29.65)$ & \\
$16-30$ & $111(20.87)$ & $125(24.23)$ & \\
$31-45$ & $107(20.11)$ & $85(16.47)$ & 0.02 \\
$>45$ & $62(11.65)$ & $43(8.33)$ & \\
Type of anaesthesia: & $509(95)$ & $483(94)$ & \\
General anaesthesia & $27(5)$ & $33(6)$ & 0.34 \\
Locoregional anaesthesia & $375(70)$ & $345(67)$ & \\
Type of surgery: & $75(14)$ & $63(12)$ & \\
Scheduled & $86(16)$ & $108(21)$ & 0.11 \\
Emergency & & & \\
Ambulatory & & \\
\hline
\end{tabular}

*Data given for 532 patients in 1993 .

$\dagger \chi^{2}$ test was used to compare age groups, type of anaesthesia, and surgery between 1993 and 1994

However, several common points emerged (fig 1 ). When a patient was not seen by the anaesthetist during a consultation or just after admission (fig 1, test ordering processes 1, 2, 3, 4 ), then tests could be ordered routinely usually by a nurse (ordering process 5). Furthermore, lack of formally organised anaesthetic consultations was highlighted in seven departments out of nine. Regular formal multidisciplinary meetings that included anaesthetists, surgeons, and nurses only occurred in the urology department. Information sheets to transmit patient data were only used in two departments, ear, nose, and throat and paediatrics. Difficulties in changing their mind and fear of legal action were two of the reasons for anaesthetists ordering unnecessary preoperative investigations.

Proposals for change were discussed and implemented within each department. Two departments chose to set up a system for formal consultation, which involved organising special consultation rooms, a secretary, and assuring the availability of anaesthetists. Other departments organised formal preoperative assessment sessions whereby anaesthetists could assess patients' fitness before surgery (fig 1 , test ordering processes $1,2,3,4)$. Regular formal meetings were set up between anaesthetists. Decision charts to help anaesthetists to order tests (according to Blery et $a l^{\beta}$ ) for low risk patients according to the local guidelines and for patients at higher risk were implemented in three departments and displayed in the nurses' room and anaesthetists' office (fig 2).

SECOND MEASUREMENT

Four months later after the implementation of the organisational changes recommended by MNP, 516 low risk patients were included in a second sample. The two samples were comparable except for patients' age (table 1). Mean (SD) age of children was 7.8 (5.0) years and for adults it was 34.07 (11.97) years. The number of patients who did not have any preoperative testing was $268(52 \%)$ in 1994 and $108(20 \%)$ in $1993\left(\chi^{2}=115 ; \mathrm{p}<0.00001\right)$. Most tests were ordered significantly less often in 1994 (table 2). Minor perioperative morbidity was
Table 2 Main types and number of preoperative tests ordered for patients at low risk from anaesthesia (ASA I) in fune 1993 ( $n=536$ patients) and fune $1994(n=516$ patients) in the University Hospital of Bordeaux, France

\begin{tabular}{llc}
\hline & \multicolumn{2}{l}{ Preoperative tests ordered } \\
\cline { 2 - 3 } Type of preoperative test * & $1993 n(\%)$ & $1994 n(\%)$ \\
\hline Blood typing & $310(58)$ & $152(29)$ \\
Haemoglobin+platelet count & $403(75)$ & $191(37)$ \\
PT+PTT $\dagger$ & $403(75)$ & $196(38)$ \\
Bleeding time & $128(24)$ & $52(10)$ \\
Fibrinogen & $340(63)$ & $122(24)$ \\
Electrolyte+glucose+urea & $173(32)$ & $57(11)$ \\
Hepatic enzymes & $30(6)$ & $6(1)$ \\
Chest $x$ ray film & $100(19)$ & $41(8)$ \\
Electrocardiogram & $128(24)$ & $54(10)$ \\
\hline
\end{tabular}

*All type of tests were ordered significantly less in 1994 than in $1993\left(\mathrm{p}<10^{-3}\right)$.

$+\mathrm{PT}+\mathrm{PTT}=$ prothrombin time and partial thromboplastin time.

noted for 11 patients $(2.1 \%)$ in 1994 and 13 patients $(2.4 \%)$ in $1993\left(\chi^{2}=0.10 ; \mathrm{p}=0.75\right)$. No patient died.

SAVINGS

1993: first sample

Mean cost of testing per patient was Fr270 (95\% confidence interval (95\% CI) 238 to $302)$; or $\$ 44$ (95\% CI 39 to 50$)$; or ECU 41 (95\% CI 36 to 46$)$.

1994: second sample

Mean cost of testing per patient was Fr132 (95\% CI 108 to 156$) ; \$ 22$ (95\% CI 18 to 26$)$; ECU 20 (95\% CI 16 to 24 ).

The estimated annual saving was Fr3.04 million (95\% CI 1.88 to 4.27) for 22000 low risk patients treated in the hospital each year.

\section{Discussion}

We found a sharp drop in the number of preoperative tests ordered by anaesthetists after local adaptation of national guidelines combined with active feedback about their practice and implementation of practice and discussion about organisational changes. Clinical audit is not an appropriate design to establish a causal relation between intervention and effect ${ }^{1921}$ and caution must be exercised in drawing such conclusions from studies of this type. Nevertheless the changes were profound and coincided not only with feedback of practice but a radical appraisal of the organisational basis for preoperative assessment.

The patients treated during the two measurement periods were similar in most respects although the age of the adults in the second group was significantly lower. This difference is only likely to impact on the results if national and local guidelines had age criteria for ordering tests. This only applies to the guidelines for ordering for ECGs, ${ }^{510}$ so we estimate that the overall effect of the age bias is likely to be slight.

The anaesthetists who took part in this study were volunteers and not randomly selected. Thus they were much more likely to be receptive to changes in practice than those who did not take up the invitation to be included in this project. We do not know yet whether the project has had any effect on the use of preoperative tests on other wards. Moreover this 
study did not look at the ordering of tests by individual people. We were able to control the timing of the two measurements-both in June-and the duration of the collection of data. The only staff turnover was that of residents but for anaesthesia they have little impact on the ordering of investigations in our hospital. Importantly there were no other national or regional initiatives on preoperative testing taking place during our study period. Thus, despite the limitations of this work we are sure that as the decrease in the ordering of tests between the two measurement periods was so large, the package of interventions was likely to be responsible.

The decrease in routine preoperative tests did not seem to increase perioperative mortality, but as this was small in this group of fit patients our study did not have sufficient power to detect a small difference. Others have already shown that more selective ordering of preoperative tests does not lead to increased perioperative mortality. ${ }^{12}$ For us the importance of measuring morbidity was as much for the professionals involved in this study who needed reassurance that the changes that they were making to their own practise were not affecting morbidity.

Our economic analysis also clearly has limitations. It does not take into account real costs, as our financial information system is not sufficiently developed to do this. Moreover, it is difficult to assess the direct financial impact on French state hospitals as this sector receives a global budget. ${ }^{22}$ However, estimated savings on all low risk standard cost patients are striking.

We think that the main contribution of this work is linking of the process of the local adaptation of national guidelines to an analysis of the organisational aspects of the practice and the emphasis that we placed on the organisational aspects of change. Improving professional practices requires more than just making sure that guidelines are correctly followed. The low impact on practice of some consensus meetings suggests that the process of change requires much more than just this. ${ }^{23}$ In our project we ensured active feedback as a central part of the audit process. The effectiveness of strategies of active feedback seems to depend on the degree of peer influence locally and on the strength of agreement between professionals. ${ }^{16}$

Professional agreement was facilitated in our hospital by involving as many as possible to consider adaptation of national guidelines, and allowing flexibility about the approach taken in each department. ${ }^{1825}$ From previous experience, a standard setting exercise and discussion of practice can help the adoption and implementation of change. ${ }^{16} 181926$

The coordinating anaesthetist here was an influential leader and his role as facilitator was crucial. He had to clarify the purpose of the project and its challenges to achieve an agreement on the guidelines. If the anaesthetists wished to enlarge the indications for ordering tests they then entered an iterative process which progressively resulted in solutions that met the national guidelines.
The importance of the organisational component of an ordering process, as shown by our project, must also be emphasised. Even if our topic was basically a problem of individual practice, we knew that organisational problems should also be taken into account. In 1991 a study found that $54 \%$ of French anaesthetists experienced organisational difficulties and $34 \%$ complained of insufficient organisation of the preoperative assessment process. $^{2}$ We therefore worked with an organisational manager (MNP). This organisational approach was particularly timely as just after our project was completed, the French Health Ministry demanded that all healthcare institutions should have an organised process for all patients to have a preoperative anaesthetic assessment. ${ }^{27}$

From a methodological point of view, we conclude from this work that even changing an apparently straightforward process such as ordering of preoperative tests is not as simple as expected. The systematic use of an organisational approach is very useful.

Usually in clinical audit in France, we only assess conformity to guidelines and assessment of implementation of change is mainly based on the subjective knowledge of the professionals. In our opinion, this is a major limit of clinical audit. In reality, most of the problems are far more complicated than expected. So, we suggest that the tools of organisational analysis should be an integral part of the audit process.

Although less likely to be part of routine practice than in other European countries, quality assurance programmes are slowly being adopted in France. ${ }^{28}$ This project was the first component of a regional approach to the implementation of quality assurance action on the topic of preoperative screening. ${ }^{29}$ Therefore, data about performances in other hospitals (general hospitals and private institutions) on preoperative ordering throughout the Region Aquitaine will be soon available. In view of anticipated limited growth in resources for health care coupled with a pressure to increase expenditure in France, unnecessary costs that have no impact on the quality of care - as in the costs of routine preoperative tests for fit people - and should be considered a waste. Professionals should be encouraged to look at their work to reduce unnecessary interventions. It is possible to implement changes but these may not be easy and require a clear organisational perspective.

We thank the Agence Nationale pour le Développement de l'Evaluation Médicale, especially Y Derenne for his methodological help, all the participating anaesthetists and surgeons (A Le Rebeller, Senegas, Durandeau, Videau, Bondonny, Brun, Dallay, Leng, Dubecq, Ballanger, Traissac, Bébear, J Le Rebeller, Amouretti, and Couzigou) and their staff, and Miss Degoul for keyboarding.

1 Hatton F, Tiret L, Maujol L, et al. Enquête épidémiologique sur les anesthésies. Premiers Résultats. Ann Fr Anesth Reanim 1983;2:332-85.

2 Charpak Y, Nicoulet I, Bléry C. Pratiques et attitudes actuelles des médecins anesthésistes en matière de prescription d'examens paracliniques préopératoires. Ann Fr Anesth Reanim 1992;11:576-83.

3 Blery C, Charpak Y, Szatan M, et al. Evaluation of protocol for selective ordering of preoperative tests. Lancet 1986;i: 139-41.

4 Blery C, Chastang C, Gaudy JH. Critical assessment of routine preoperative investigations. Effective Health Care 1983; 1:111-14 
5 Goldberger AL, O'Konski M. Utility of the routine electrocardiogram before surgery and on general hospital Med 1986;105:552-7.

6 National study by the Royal College of Radiologists. Preoperative chest radiology. Lancet 1979;ii:83-6.

7 Kaplan EB, Sheiner LB, Boeckmann AJ, et al. The usefulness of preoperative laboratory screening. $\mathscr{f} A M A$ 1985;253:3576-81.

8 Rohrer MJ, Michelotti MC, Nahrwold DL. A prospective evaluation of the efficacy of preoperative coagulation testing. Ann Surg 1988;208:554-7

9 McCleane GJ. Urea and electrolyte measurement in pre-operative surgical patients. Anaesthesia 1988;43:413-5.

10 Agence Nationale pour le Développement de l'Evaluation Médicale (ANDEM). Evaluation des examens préopératoires. ANDEM, eds. Paris : ANDEM, 1992.

11 Fagnani F. Elements statistiques sur la pratique des examens radiologiques du crâne et du thorax. Réanimation Soins radiologiques du crâne et du thorax. Rean
Intensifs Medicine d'Urgencé 1990;6:415-6.

12 Roberts CJ, Fowkes FGR, Ennis WP, et al. Possible impact of audit on chest $x$ ray requests from surgical wards. Lance 1983;ii:446-7.

13 Ellis WB, Sensky T. A clinician's guide to setting up audit. BMF 1991;302:704-7.

14 Mc Kee CM, Lauglo M, Lessof L. Medical audit: a review. $\mathcal{f}$ $R$ Soc Med 1989;82:474-8.

15 Fowkes FGR, Davies ER, Evans KT, et al. Multicentre trial of four strategies to reduce use of radiological tests. Lancet 1986;i:367-70.

16 Mugford M, Banfield P, O'Hanlon M. Effects of feedback of information on clinical practice: a review. BMF 1991;303 398-402.

17 Lomas J, Enkin M, Anderson GM, et al. Opinion leaders $v$ audit and feedback to implement practice guidelines. Delivery after previous cesarean section. $\mathcal{F} A M A 1991 ; 265$ : 2202-7.

18 Stocking B. Promoting change in clinical care. Quality in Health Care 1992;1:56-60.
19 Grimshaw JM, Russell IT. Effect of clinical guidelines on medical practice: a systematic review of rigorous evaluations. Lancet 1993;342:1317-22.

20 Caisse Nationale d'Assurance Maladie des Travailleurs Salariés. Nomenclature Générale des Actes Professionnels. Arrété du 27 Mars 1972 et suivants. Paris: Union des Caisses Nationales de Sécurité Sociale (UCNSS), 1992.

21 MacRae K. Validity of assessing change through audit. BMF 1994;309:18-19.

22 Giraud A. Medical audit in France: historical perspective. BMF 1992;304:426-8.

23 Giraud A, Jolly D. Les conférences de consensus ont-elles eu impact souhaité sur les pratiques médicales? In: Giraud A, Jolly D, eds. Le consensus en médecine. Analyse et bilan des conférences de consensus dans le monde. Paris: AP-HP Doin, 1991:125-30.

24 Mozes B, Lubin D, Modan B, et al. Evaluation of an intervention aimed at reducing inappropriate use of preoperative blood coagulation tests. Arch Intern Med 1989;149: 1836-8.

25 Eccles M, Clapp Z, Grimshaw J, et al. North of England evidence based guidelines development project: methods of guidelines development. BMF 1996;312:760-2.

26 Russell IT, Wilson BJ. Audit: the third clinical science? Quality in Health Care 1992;1:51-5.

27 Ministère des affaires sociales, de la santé et de la ville. Décret n 94-1050 du 5 Décembre 1994 relatif aux conditions techniques de fonctionnement des établissements de sant en ce qui concerne la pratique de l'anes fiant le code de la sant publique. Fournal Officiel République France 8 Décembre 1994.

28 Amouretti M, Beraud C, Saint-Martin E. Medical audit in France: from ideal to reality. $B M 7$ 1992;304:428-30.

29 Michel P, Capdenat E, Raymond JM, et al. Regional experience of evaluation of professional practice and quality assurance implementation in Aquitaine. Int $\mathcal{f}$ Qual Health Care 1997;9:221-3. 